\author{
O. Shmatko ${ }^{1}$, V. Aleksiyev ${ }^{2}$, Liang Dong ${ }^{1}$ \\ ${ }^{1}$ National Technical University "Kharkiv Polytechnic Institute", Kharkiv, Ukraine \\ ${ }^{2}$ Simon Kuznets Kharkiv National University of Economics, Kharkiv, Ukraine
}

\title{
AN ALGORITHM FOR SEA-SKY LINE DETECTION UNDER VISIBLE SEA IMAGE
}

\begin{abstract}
Subject of research is the process of sea-sky line detection, based on color feature. The purpose of this work is to develop the method is based on color feature as well as textural information. It consists of sea sky region extraction and horizon detection, which is more precise and fast no matter in the sceneries created by camera mounted on board or on shore. The tasks to be solved is: to propose the new linear fitting metric in sea-sky line extraction. The following results were obtained. The proposed linear fitting method was studies. The performance of proposed horizon detection method is estimated by comparison to other 3 state-of-art methods based on 13 challenging testing videos under different circumstances. The 3 methods are: the method based on discriminates and eigenvalues of covariance matrices in RGB space (H-DE); the method adopting probability distribution functions of sea and sky region (H-PDF) and the method by multi-scale cross modal linear feature (MSCM). The video sequences can be classified into two categories: the camera mounted on board and with camera mounted on shore horizon. Conclusion. The proposed linear fitting method can rectify the outlier values. The experimental results on a sequence of test videos demonstrate that the proposed sea-sky line detection method has a higher accuracy and it is more robust and efficient than other existed methods.
\end{abstract}

Keywords: Sea-sky line; extract the sea-sky line accurately even from low-resolution image; novel horizon detection method for maritime environment.

\section{Abstract}

Sea-sky line is one of the most important semantic boundaries in sea-sky images. We design an algorithm consisting of three stages: region extraction, color segmentation and line detection. At first, the region extraction is performed by a spatial-contextual texturebased model and each region is assigned a probability for constructing a belief map to identify sea-sky region. Then, the color segmentation algorithm calculates a series of adaptive thresholds so as to create corresponding breakpoints. Finally, a novel voting method is developed to reduce the computation and the expenses on storage for line detection. Under various sea and sky background, our algorithm can detect the partially occluded sea-sky line precisely.

\section{Introduction}

Sea-sky line, as a kind of horizon, bisects sea and sky from sea-sky background image. Sea-sky line plays an important role in maritime surveillance which has been applied to several domains. Because targets on the remote distance always firstly appear near the sea-sky line, the sea-sky line is located to detect the remote targets. Besides, the sky region is regarded as the background, which is excluded to narrow the target searching area and reduce computation cost. Unmanned aerial vehicle (UAV) works on the sea, whose pitch angle and roll angle can be estimated by sea-sky line to automatically adjust its attitude. As the sea-sky line become popular in maritime surveillance, more and more methods are proposed to extract sea-sky line.

A two dimensions parameter space is constructed by adjusting bank angle and pitch angle so as to indicate the location of assumed sea-sky line. Based on color feature, covariance matrices of sea and sky are created respectively. The criterion using determinants and sumof-eigenvalues is proposed to determine the true sea-sky line [2]. In [3] the probability distribution function is introduced for describing the gray distribution of image.
The line with maximum Bhattacharyya distance is regarded as the true sea-sky line. Shen et al. [4] proposed a modified algorithm of $\mathrm{H}-\mathrm{HC}$ with double-side narrow band which reduces the influence from wave clutters to some extent. Cornell et al. [5] simplified the calculation by a circular mask. Within the circular mask, the image is segmented into sea region and sky region using OTSU algorithm [10]. The centroid coordinate in each region can be acquired by the average values of $x$ and $y$. The position of sea-sky line is derived directly without extra extraction of the linear feature. However, the method is only conducted with clear sky over flat terrain. In [6], the horizon angle ranging from $0^{\circ}$ to $180^{\circ}$ is divided into several parts equally. Within each part, edge pixels project to a line crossing origin. As the maximum projection value may not correspond to the real sea-sky line, several metrics are used such as the distribution of the real sea-sky line projection is symmetric and narrower than other edges projection; the sea-sky line project must be a local extreme value. Edges produced by waves and clouds also satisfy these metrics which are applicable to sky-ground situation but not work well under sea-sky circumstance. Luo et al. [7-8] designed a model composed of color classification and physical-motivated signature validation, which is only effective under specific circumstance with clear and light-blue sky at daytime. Dilip et al. [9] proposed an algorithm for seasky line detection called multi-scale cross modal linear feature. By multi-scale media filtering, the linear feature is extracted by Hough transform and the intensity variation over different scales. Affirm score composed of geometric score and goodness score are calculated, the largest value of which indicates the true sea-sky line. The method can extract the sea-sky line accurately even from low-resolution image or under the circumstance that horizon is partially occluded by other objects. But the method is easily influenced to waves with huge computational complexity.

The paper is organized as follows. In Section 2, the physical characteristics around horizon in maritime are 
investigated. According to these characteristics, abnormal values are eliminated and a statistical gray-level cooccurrence matrix is constructed. Then a weighted contrast is designed to extract texture feature. Based on color feature, the process of sea-sky line detection is executed. A series of thresholds are obtained by OTSU method to find appropriate split points. Thus a new metric linear fitting method is desired using the split points. Section 3 presents experimental results and discussion on the performance of methods. Conclusion and suggestions for future research are drawn in Section 4.

\section{Algorithm}

Clouds influence color distribution of sky region which also constructs textural features while features of sea region are consisted of light refraction and reflection from waves. To extract sea-sky line, sky with its clouds can be classified into one class and sea belongs to another class. What we should to do is that reduce the difference within the class without weakening the difference between classes. In order to illustrate three color distributions, we extract 1-D traces within the image along blue sky-to-cloud direction. As shown in Fig.1 (a), we find that in blue channel color changes between blue sky and white clouds is not as significant as in red channel and green channel. In cloud region whose color is seen as whitish, all three channels reach a high level in clouds [1] but only the blue channel in blue sky has a high value as clouds. And in Fig. 1 (b), three color distributions are similar to each other. One of them can represent the others. It means that we can adopt the blue channel value to transform the image from RGB color space to gray space under this circumstance. This principle is also applicable to condition associating with sunrise and sunset.
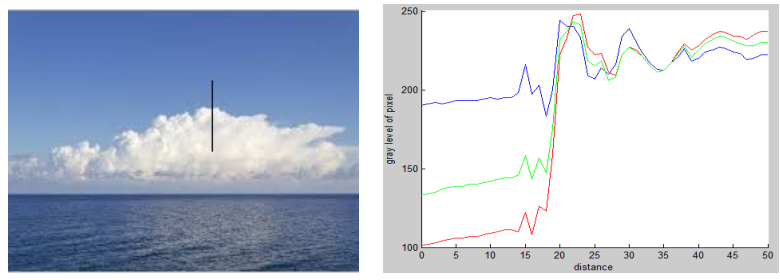

a
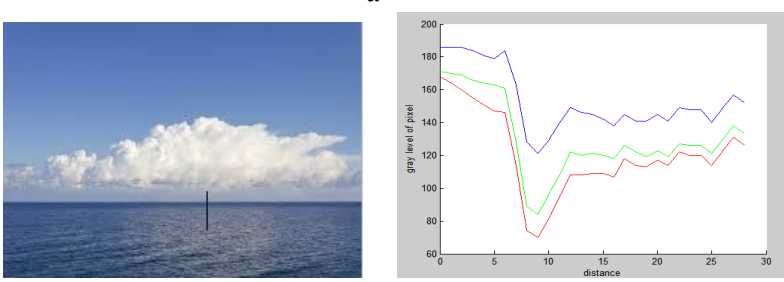

Fig. 1. The first image of shows a trace (in black color) going through clear blue sky and white clouds, crossing sky to deep blue sea. The second image illustrates corresponding color records of three channels (blue, green and red respectively)

For an original image $I$ with $M \times N$ resolution cells, its gray image is described as:

$$
I_{\text {gray }}=f(x, y)_{M \times N} .
$$

Where $f(x, y)$ is gray level of pixel at position $(x, y)$. We randomly select a region whose height or width should be equal to height or width of image and calculate average value of each channel. The value of $f(x, y)$ is computed by following equation:

$$
f(x, y)= \begin{cases}R(x, y) & \text { if } R>G, R>B \\ G(x, y) & \text { else if } G>R, G>B \\ B(x, y) & \text { otherwise, }\end{cases}
$$

where $R(x, y), G(x, y), B(x, y)$ represent value of red, green, blue channel at position $(x, y)$ respectively while $R G B$ respectively represent the average value of threedistinction image's color channel of red, green, blue in selected region. Based on $Y U V$ model, there is a traditional formula to acquire a gray image from original $R G B$ image:

$$
\begin{gathered}
f(x, y)=0.299 \times R(x, y)+ \\
+0.587 \times G(x, y)+0.114 \times B(x, y) .
\end{gathered}
$$

Fig. 2 shows the result of transformation by two different formulas. From Fig. 2 we find that the diversity between blue sky and white clouds is weakened obviously and the difference between sky and sea is reduced slightly by proposed formula. It is helpful to separate the sky from sea.

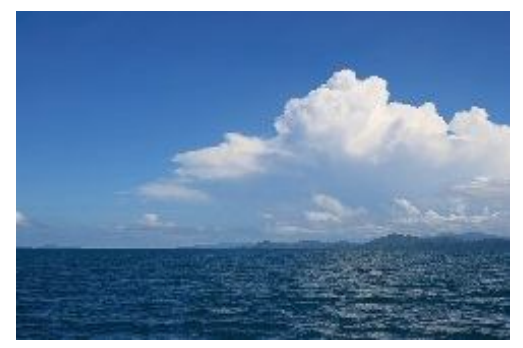

a - Original image
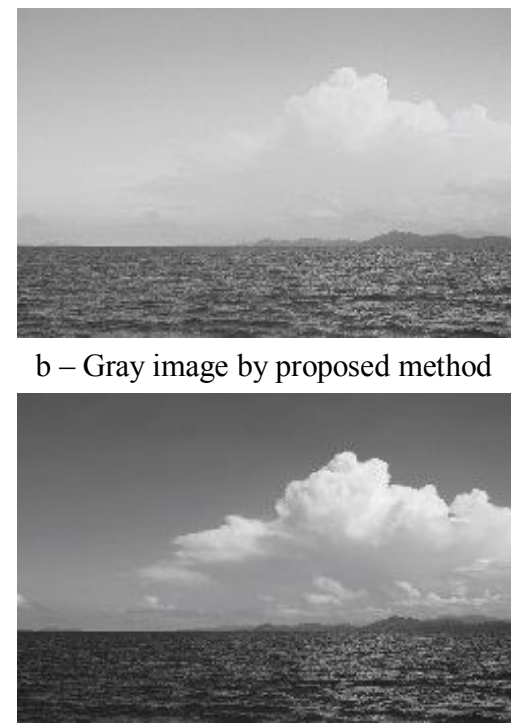

c - Gray image by traditional method

Fig. 2. The obtained gray images using different formulas.

For that sea always has darker blue color comparing to sky, color as the most prominent feature, which can be directly used to identify sky and sea in the most circumstance. But sky with saturated blue at the top and sea with lights from reflection and scattering 
may disturb sea-sky line extraction. On the basis of Rayleigh's law, the color of sky gradually desaturates from zenith to sea-sky line. The region appearing near the horizon is almost white for scattering effect caused by particles in air. To eliminate saturation effect on the top of image and reflection light on large area appearance of sea, we can extract sea-sky region, including both partial sea and sky, to locate sea-sky with less disturbance. Our experimental images show that for true clear sky region or overcast sky region even colortinted sky region (at sunrise or sunset), the detected sky region have a near uniform distribution. Because the light scattering in some color channel is approximately homogeneous, the sky region also appears fairly homogeneous in terms of color as well as textural feature. But the light reflection and scattering on the appearance of sea cause them inhomogeneous. We use textural feature to describe characteristics of sea and sky. As the spatial relationship is regard as the function of distance between two pixels, the textural feature of region can be expressed by gray-level co-occurrence matrix. Gray-level co-occurrence matrix is consisted of the joint numbers by combination of every two gray level $i$ and $j$ along direction $\Theta$, with distance $d$. The co-occurrence matrix is defined as:

$$
\begin{gathered}
P(i, j, d, \Theta)= \\
\#\{[(x, y),(x+m, y+n)] \mid f(x, y)=i, f(x+m, y+n)=\mathrm{j}\},
\end{gathered}
$$

where $\quad m=d \cos \Theta, \quad n=d \sin \Theta, \quad(x, y) \quad$ and $(x+m, y+n)$ are positions of two pixels in image, \# represents the number of elements in this set; $\Theta$ $\left(\Theta=0^{\circ}, 45^{\circ}, 90^{\circ}, 135^{\circ}\right)$ denotes the angle between horizontal direction and the line connected by two pixels.

To reduce the computation, we rescaled the values from 8 bit to 4 bit.

The rescaled formula is shown as:

$$
f(x, y)=f(x, y) / 16,
$$

a normalized matrix is defined as:

$$
P(i, j, d, \Theta)=P(i, j, d, \Theta) / R,
$$

where $R$ is the total number of pixel pairs.

We have got gray-level co-occurrence matrix and need to evaluate the complex of textural feature. The contrast, as an evaluated approach of textural features, is calculated as:

$$
C=\sum_{i} \sum_{j}(i-j)^{2} P(i, j, d, \Theta) .
$$

As gray distribution of sky and sea is anisotropic, textural features from all four angles are useful for constructing gray-level co-occurrence matrix. We add up values from four directions as the final textural feature value. For characteristics of sea-sky images, we classify them into four classes: overcast images with clouds, images containing rough waves, color-tinted images with strong lights from scattering and reflection as well as normal images including clear sky and calm sea. These are showed as Fig. 3.
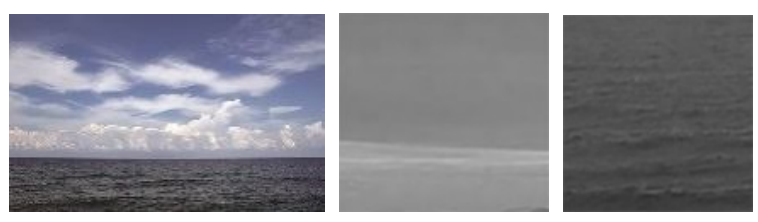

a - overcast image

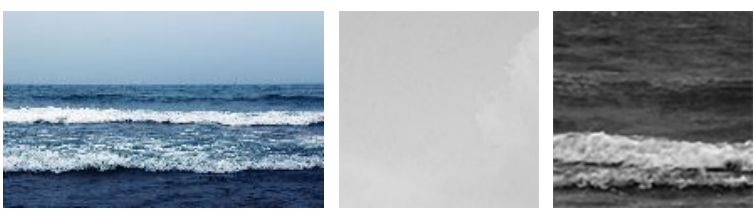

$b$ - image with rough waves
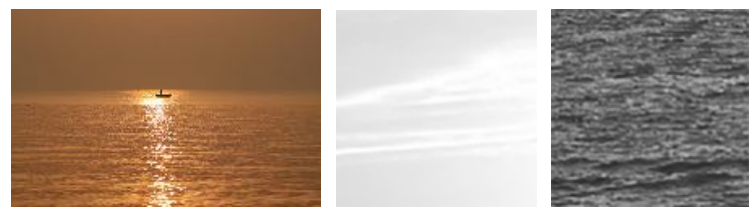

c-color-tinted image
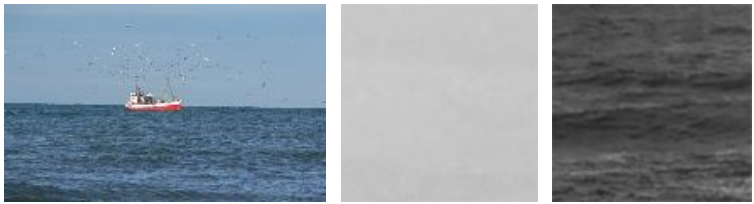

$\mathrm{d}$ - normal image

Fig. 3. The first column of a, b, c, d is original sea-sky image. The second column describes their sky region. The last column is from their sea region.

To illustrate the difference of sky region and sea region, we calculate textural features of them from Fig. 3. We set $d$ starting at $d=1$ and the increasing step is one pixel. The biggest value of $d$ is 30 . The normalized contrast values of the textural feature calculated from the sky and sea sub-images are shown in Fig. 4.

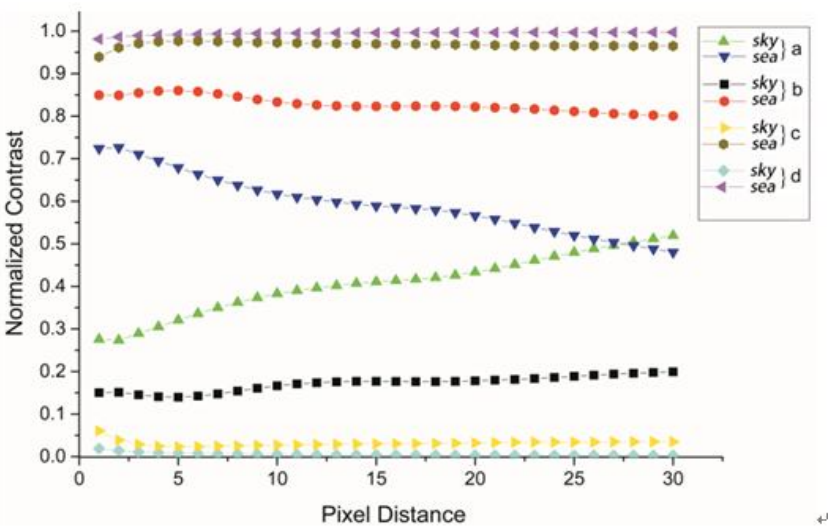

Fig. 4. The normalized contrast values with the variation of $d$

From Fig.4, when $d=2,3$ the normalized contrast value performs better to get an obvious differentiation between the sky region and sea region. In all four kinds of scene, the textural feature of sea region is more complex than sky region with certain pixel distance [8]. Especially in color-tinted image and image with rough sea, the textural features of sea and sky are even not in the same order. But for image with overcast sky, the sea region is more complex than the sky region only when the pixels distance less than 28 , because the thickness of clouds is not 
unformed. Lights scatter by particles in clouds, which cause variable gray distribution and construct more complex textural features comparing to other scenes.

We design a sliding window and calculate textural feature value in each time window slides. The size of sliding window cannot be too small because textural features are based on statistics. As well the window size should not be so large that it includes both sky and sea which confuses discrimination. There is no identical standard to devise the size of window. According to experimental results, we set the size of sliding window at a resolution of $m \times n$, where $m=[\mathrm{M} / 15], \mathrm{n}=[\mathrm{N} / 15]$, $\mathrm{M}$ is the number of original image's rows while $N$ represents the amount of columns. The sliding window starts moving on the top-left along the vertical direction. The moving trajectory is given in Fig. 5, a.
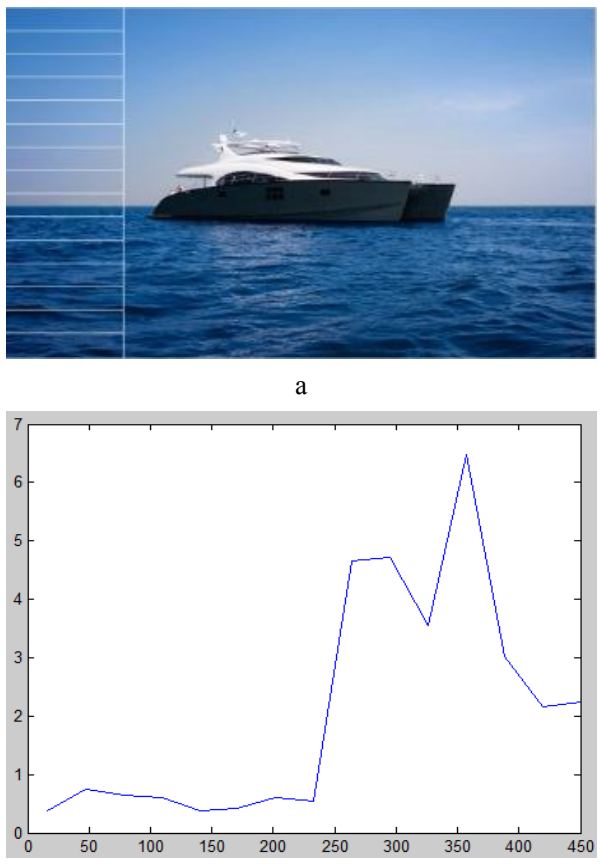

b

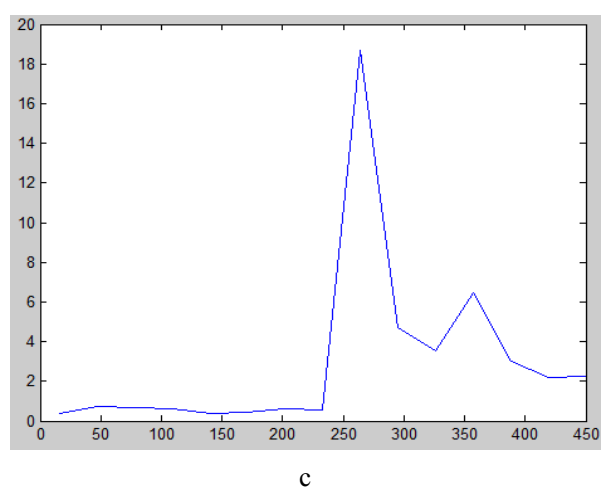

Fig. 5. Each small white rectangular shows the size of sliding window. Window moves along the vertical direction from zenith to nadir. $b$ - shows a series of datas with oulier\$ $\mathrm{c}$ - shows datas without outlier

We compute textural features in each sliding window and get a series of values, which are showed in Fig. 5, b. It clearly can be seen that the curve increases sharply near the conjunction of sea and sky on which existing a specially high value exceeds over 18 . This oulier value is created by the window including both sea and sky where gray distribution changes violently. We eliminate this abnormal value (as Fig. 5, c) and these remining datas distribute like a s-shape curve. Although within one sliding window textural value of sea larger than sky's, there are still some special condition as Fig. 5, a: sliding windows containing sky and sea may have the maximum textural value over all image under which the next regions are believed to be sea with high confidence(the seed region of sea). On the same time, the window with the minimum value is defined as sky region in low confidence(the seed region of sky). Based on experimental results, if the textural value in some window is less than four times of minimum textural value and no more than a quarter of maximum textural value, corresponding windows belong to sky. Every seed region of sea is assigned a belief value of 0.99999 , and each seed region of sky is given a belief value of 0.00001 . We also need to assigned belief values to other regions, in other words sliding windows, which are not seed region. A logistic model of sea is applied to a classification stage for assigning a belief value to each region. The logistic model is represented as:

$$
f(x)=\frac{1}{1+e^{-(x-a) / c}}
$$

Where $\alpha$ is the offset of logistic function on $\mathrm{x}$-axis. $c$ represents the extent of inclination for curve: the value is higher, the curve is steeper. $x$ is the location of seed region in original image $f(x)$ is belief value corresponding to each $x, f(x) \in(0,1)$. We takes logarithm of logistic function as:

$$
\begin{aligned}
& \ln \left(\frac{1}{f(\mathrm{x})}-1\right)=\ln \left(\exp \left(-\frac{x-a}{c}\right)\right)=-\frac{x}{c}+\frac{a}{c} . \\
& \text { Set } y=\ln \left(\frac{1}{f(\mathrm{x})}-1\right), \text { so } y=-\frac{x}{c}+\frac{a}{c} .
\end{aligned}
$$

The logistic function has been transformed into a linear function. Suppose that the number of seed region is $N$, we have a series fitting points consisting of the location of seed region $x_{\text {seed }}$ and their belief values $y_{\text {pro }}$. We should adopt a method to minimize the sum of squraed residuals between observed belief value and fitted belief value. The method of least square, as an approach in linear regression, can be used in data fitting.

When two coefficients of logistic function has got, the fitting curve of Fig. 5, a is descibed as Fig. 6.

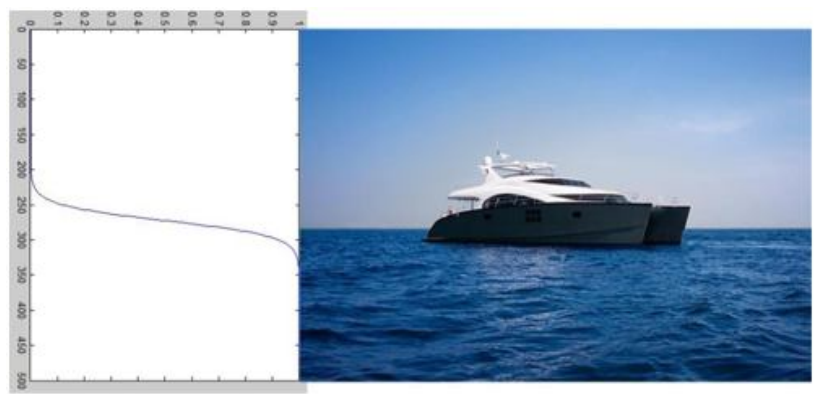

Fig. 6. The logistic curve of Fig. 5 is based on the location of seed region and their belief value 
When the belief value of area approximates near 1 , the area is definitely sea area. Otherwise, when the belief value decreases near 0 , its corresponding area all belongs to sky. Some areas with probability between 0 and 1 are hardly to be defined as sea or not. We called these area as sea-sky area. Sea-sky area eliminates the top region of original image on which satured effect often apears. Sea region on the sea-sky area is almost white. And on the sea-sky area, the reflecting light scatters more times from appearance of sea whose color becomes deeper dark blue. The boundary of sea-sky region is decided by predefined belief values where the smallest value decides the highest boundary of sea-sky area and the largest value sets the lowest boundary. We define two belief value as the largest one is $P_{l \text { arge }}$, another probability is $P_{\text {small }}$. The boundary of sea-sky region is located in a definite interval. If $P_{l \text { arge }}$ increases by degree, the area of sea as $x_{\text {low }}$ on the seasky region would decrease gradually. On the same time, when $P_{\text {small }}$ decreases, the value of $x_{\text {high }}$ increases and area of sky region becomes more larger. In order to obtain adequte area of sea and sky, we set $P_{\text {large }}=0.99, P_{\text {small }}=0.01$. Under this condition, seasky region is extracted as Fig. 7 a)shows.

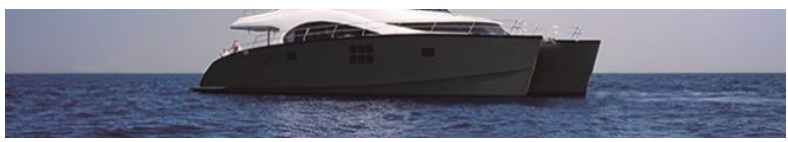

a

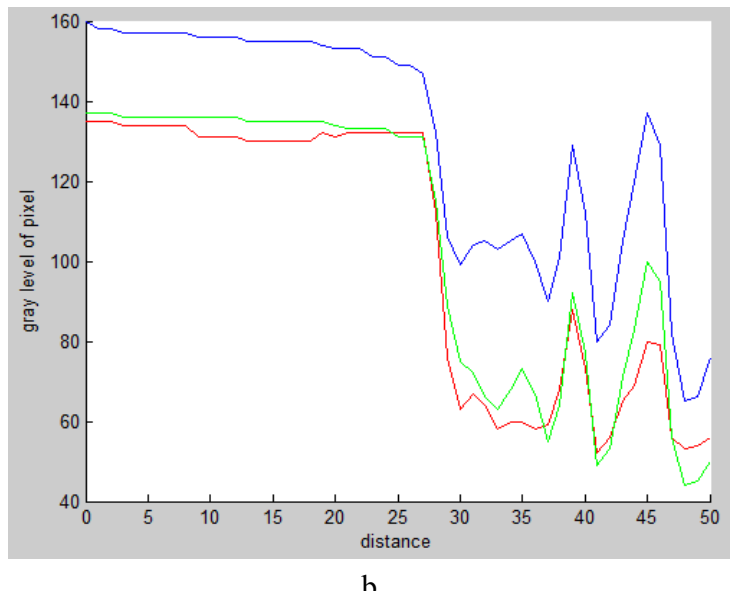

b

Fig. 7. Extracted sea-sky region with occluding boat

Above of sea-sky region has bluish color and the part of sea shows dark blue color. It is obvious that seasky region is partitioned into two classes according to their color distribution. We can use color feature to find a threshold distinguishing these two regions and extract sea-sky line as a boundary between them. We randomly select one of the columns (not includes boat) in Fig.7 a and its gray distribution is showed in Fig.7 b. Gray histogram is assumed to have a bimodal distribution with a sharp change near the boundary of two classes. We adopt OTSU algorithm searching for the threshold that maximize the inter-class variance and minimize the intra-class variance, which is described as:

$$
\sigma_{b}^{2}(\mathrm{t})=w_{1}(t) w_{2}(t)\left(\mu_{1}(t)-\mu_{2}(t)\right)^{2},
$$

where $t$ is the threshold when inter-class variance $\sigma_{b}^{2}$ reaches the maximum value $w_{1}(t), w_{2}(t)$ are probabilities of two classes by threshold while $w_{1}(t)$, $w_{2}(t)$ are class means:

$$
\begin{gathered}
w_{1}(t)=\sum_{i=0}^{t-1} P(i), w_{2}(t)=\sum_{i=t}^{g-1} P(i) ; \\
\mu_{1}(t)=\sum_{i=0}^{t-1} \frac{i P(i)}{w_{1}(t)}, \mu_{2}(t)=\sum_{i=t}^{g-1} \frac{i P(i)}{w_{2}(t)},
\end{gathered}
$$

where $g$ is gray level, $P(i)$ is the probability under gray-leve $i$.

When sky is clear whose light is bluish, both sky region and sea region have their identical color features. But obstacles, as Fig. 7 a, appears on the sea-sky line disturbs gray distribution of sea-sky area, which produces several undesirble false positives. We equally divide sea-sky region into $n$ parts $(n=20)$ along the horizontal direction and calculate threhold in each part. If the part occluded by obstacles (i.e boats, waves, islands), it will produce a outlier. The part without any obstacles, or these obstacles can not disturbs gray distribution evidently, it creates a threshold accurately. A sequence of thresholds have been obtained, by which we locate coordinates of segment in each part. Fig. 8 illustrates 20 candidate coordinates the are computed for the image of Fig. 7, a. We should eliminate those outliers and extract sea-sky line using reminder points.

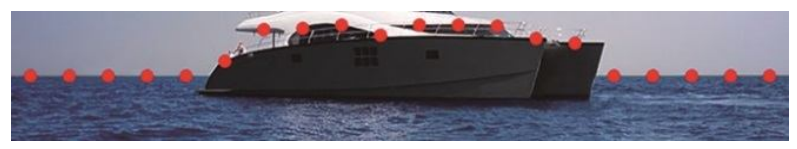

Fig. 8. 20 candidate coordinate for segmentation

A straight line pattern is described as:

$$
y_{i}=k x_{i}+b, i=1,2, \ldots n,
$$

where $\left(x_{i}, \mathrm{y}_{i}\right)$ is edge points on the same straight line. $k$ is the linear slope and $b$ is the intercept. $n$ represents the number of edge points. Every two points can construct a linear equation. Each point set $\left(\left(x_{i}, y_{i}\right),\left(x_{j} y_{j}\right)\right), i \neq j$ will obtain a pair of parameters $(\Theta, b), \Theta=\arctan k$. We use angle $\Theta$ to quantify the gradient of straight line instead of the slope $k$ because of $\Theta \in\left(-90^{\circ}, 90^{\circ}\right)$ which has a definite boundary while $k \in(-\infty,+\infty)$. In Fig. 8 every two candidate coordinates is connected in order so as to create a set of coordinate pairs

$$
\left\{\left(\left(x_{i} y_{i}\right),\left(x_{j} y_{j}\right)\right)\right\}, i<j, i \in[1, n-1], j \in[2, n]
$$

and their corresponding parameter pairs $\left\{\left(\Theta_{i, j}, b_{i, j}\right)\right\}$. Once a pair of these parameters is got, $\operatorname{Count}\left(\Theta_{i, j}, b_{i, j}\right)$ as an accumulator, will be increased by one. Some connections is illustrated in Fig. 9. 


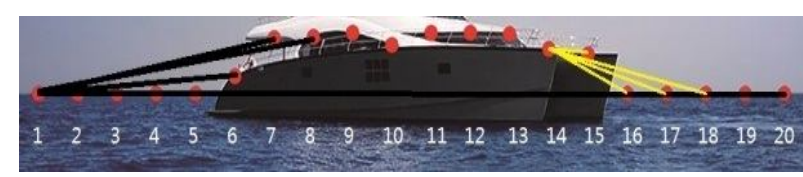

Fig. 9. Some connections between coordinates. The straight line in black color represents the connections between the first coordinate(No.1) and other coordinates. The yellow lines connect the coordinate, whose sequence number is 14 , with its following coordinates

Total number of connections is:

$$
\sum_{i=1}^{n-1} \sum_{j=i+1}^{n} \operatorname{Count}\left(\Theta_{i, j}, b_{i, j}\right)=1+2+\ldots+(n-1)=\frac{n(n-1)}{2} .
$$

All of coordinates on the sea-sky line, like $(1,2,3,4,5,16,17,18,19,20)$, can construct the same straight line. But for coordinates in outlier, like point No. 14, connections in yellow color may belong to different linear equations.

Suppose that under extreme circumstances, all coordinates in outlier arrange in the same straight line of which the amount is $m$. If we could extract the sea-sky line accurately, it should satisfy

$$
\frac{n(n-1)}{2}>m(m-1) \rightarrow m<\frac{n}{2} .
$$

In fact, as Fig. 9 shows, these outliers are not in the same stright line in most cases. It means even the length of obstacles are more than half of the image width, we can also truely find the sea-sky line. After all parameter pairs $(\Theta, b)$ have been obtained, we define $\left(\Theta_{\max }, b_{\max }\right)$ as the parameter of sea-sky line if its value in accumulator is the largest one. The conclusion of procedure is: at first we partition coordinates by angle $\Theta$ and intercept $b$ up to a certain tolerance; then count the number of elements in each group that is done by corresponding accumulators; finally, validate the group which has the largest number of elements.

Step 1. Parameter calculation

A linear function is fitted by at least two points. When we have two ponts $\left(x_{i}, y_{i}\right),\left(x_{j} y_{j}\right)$, the linear equation is written as:

$$
y=\frac{y_{j}-y_{i}}{x_{j}-x_{i}} x+\frac{x_{j} y_{i}-x_{i} y_{j}}{x_{j}-x_{i}},
$$

where $i<j, i \in[1, n-1], j \in[2, n], x_{j} \neq x_{i}$.

And the angle $\Theta$ and the intercept $b$ are:

$$
\Theta=\arctan \frac{y_{j}-y_{i}}{x_{j}-x_{i}} ; \quad b=\frac{x_{j} y_{i}-x_{i} y_{j}}{x_{j}-x_{i}} .
$$

We desigh a set $S$ to deposit parameter pair $(\Theta, b)$. Step 2. Voting

When we get a parameter pair $(\Theta, b)$ by step 2 , we should judge whether $(\Theta, b)$ have existed in set $S$ or not. If exist, the correspoding accumulator $\operatorname{counter}(\Theta, b)$ increases by one. Otherwise, $(\Theta, b)$ will be added into set $S$. For that small waves and reefs appearing on sea-sky line make the position of line distorted.

We set up two predefined tolerances, $\tau_{\Theta}$ for angle and $\tau_{b}$ for intercept, so as to reduce distortion effects. For $\forall\left(\Theta_{l}, \mathrm{~b}_{l}\right) \in \mathrm{S}$, if exits:

$$
\left|\Theta-\Theta_{l}\right|<\tau_{\Theta} \text { and }\left|b-b_{l}\right|<\tau_{b} .
$$

We updates the parameter pair as:

$$
\begin{aligned}
\Theta_{l} & =\frac{\Theta+\Theta \operatorname{counter}\left(\Theta_{l}, \mathrm{~b}_{l}\right)}{\operatorname{counter}\left(\Theta_{l}, \mathrm{~b}_{l}\right)+1} ; \\
b_{l} & =\frac{b+\operatorname{bcounter}\left(\Theta_{l}, \mathrm{~b}_{l}\right)}{\operatorname{counter}\left(\Theta_{l}, \mathrm{~b}_{l}\right)+1} .
\end{aligned}
$$

Then the correspoding accumulator will increase as:

$$
\operatorname{counter}\left(\Theta_{l}, b_{l}\right)=\operatorname{counter}\left(\Theta_{l}, b_{l}\right)+1 \text {. }
$$

If not, we put $(\Theta, b)$ into set $S$ as a new element. The Step 2 continues until all parameter pairs are used.

Step 3. Validation

We search all over of the set $S$ to find the maximum value in their corresponding accumulators. Suppose that the value of $\operatorname{Count}\left(\Theta_{\max }, b_{\max }\right)$ is the largest, $y=\tan \Theta_{\max } x+b_{\max }$ is regraded as the linear equation of sea-sky line. The result of extraction by algorithm is showed in Fig. 10.

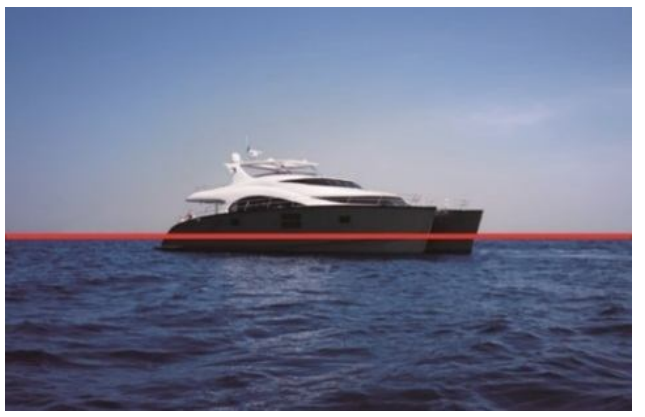

Fig. 10. The result of sea-sky line extraction

\section{Experiments}

The performance of proposed horizon detection method is estimated by comparison to other 3 state-ofart methods based on 13 challenging testing videos under different circumstances. The 3 methods are: the method based on discriminates and eigenvalues of covariance matrices in $R G B$ space $(H-D E)$ [2]; the method adopting probability distribution functions of sea and sky region $(H-P D F)$ [3] and the method by multi-scale cross modal linear feature (MSCM) [9]. The video sequences can be classified into two categories: the camera mounted on board and with camera mounted on shore horizon. For camera mounted on shore, the location of sea-sky line remains stably. However, for camera mounted on board, the location of sea-sky line changes along the vessel. Under this condition, the seasky line detection would be influenced significantly.

To evaluate the performance of proposed method, in this experiment parameter of angle deviation $\tau_{\Theta}$ is set to 0.5 and the intercept deviation $\tau_{b}$ is equal to 3 . 
The details of video sequences used in experiments are described in Table $1(\mathrm{~N}$ - name of test sequences; $\mathrm{T}$ - the number of ground truth/frames; $\mathrm{TT}$ - the total number of frames).

Table 1 - Video sequence in the experiments

\begin{tabular}{|c|c|c|c|c|c|}
\hline $\mathbf{N}$ & $\mathbf{T}$ & $\mathbf{N}$ & $\mathbf{T}$ & $\mathbf{N}$ & $\mathbf{T}$ \\
\hline 1 & 299 & 6 & 255 & 11 & 299 \\
\hline 2 & 279 & 7 & 299 & 12 & 539 \\
\hline 3 & 299 & 8 & 299 & 13 & 502 \\
\hline 4 & 299 & 9 & 299 & \multirow{2}{*}{ TT } & \multirow{2}{*}{4255} \\
\hline 5 & 288 & 10 & 299 & & \\
\hline
\end{tabular}

Several standards are proposed to evaluate the performance of horizon detection method comparing to manual denoted results. At first, the angle $a$ between horizon and the horizontal edge of image which indicates the inclination of horizon. $Y$ is the vertical distance from the center point of upper edge in the image to horizon and it is used to mark the location of horizon [9]. The errors of angle $a$ and distance $Y$ are produced by the subtraction of detected results and ground truth at every frame.

Based on 13 test maritime videos, the performances of 4 methods are evaluated as Table 2 and 3.

\section{Table 2 - Average Center Location Error Y (in pixel)}

\begin{tabular}{|c|c|c|c|c|}
\hline \multirow{2}{*}{$\begin{array}{c}\text { Name of } \\
\text { test } \\
\text { sequences }\end{array}$} & \multicolumn{4}{|c|}{ Method } \\
\hline & $M S C M$ & $H-P D F$ & $H-D E$ & Proposed \\
\hline 1 & 340.8003 & 158.2167 & 34.5042 & 2.3870 \\
\hline 2 & 247.5191 & 24.3547 & 22.9409 & 3.4670 \\
\hline 3 & 306.0614 & 25.2960 & 20.0490 & 3.0749 \\
\hline 4 & 105.1453 & 25.6921 & 52.2371 & 5.8420 \\
\hline 5 & 283.2996 & 139.0549 & 16.7897 & 3.0327 \\
\hline 6 & 243.2897 & 15.4826 & 29.8568 & 1.8821 \\
\hline 7 & 101.1494 & 13.8743 & 20.8121 & 2.7234 \\
\hline 8 & 67.9964 & 19.2581 & 48.9061 & 2.7236 \\
\hline 9 & 279.6231 & 39.5646 & 26.1926 & 6.5724 \\
\hline 10 & 213.1621 & 59.2639 & 35.9400 & 7.7864 \\
\hline 11 & 3.3323 & 66.3006 & 33.3258 & 4.6951 \\
\hline 12 & 13.2109 & 135.8365 & 18.4610 & 11.9131 \\
\hline 13 & 12.3280 & 28.7704 & 45.5998 & 1.8326 \\
\hline$Y$ & 152.8733 & 52.8953 & 32.0193 & 4.7867 \\
\hline
\end{tabular}

\section{Table 3 - Average Center Location Error $\alpha$ (in degree)}

\begin{tabular}{|c|c|c|c|c|}
\hline \multirow{2}{*}{$\begin{array}{l}\text { Name of } \\
\text { test } \\
\text { sequences }\end{array}$} & \multicolumn{4}{|c|}{ Method } \\
\hline & $M S C M$ & $H-P D F$ & $H-D E$ & Proposed \\
\hline 1 & 2.0608 & 2.6242 & 3.6478 & 0.0928 \\
\hline 2 & 1.9307 & 1.3691 & 3.8127 & 0.1440 \\
\hline 3 & 1.799 & 1.4702 & 3.3448 & 0.1650 \\
\hline 4 & 1.1927 & 1.4903 & 5.5584 & 0.2747 \\
\hline 5 & 1.9161 & 2.9089 & 3.1428 & 0.1159 \\
\hline 6 & 1.7038 & 2.8763 & 2.8679 & 0.1342 \\
\hline 7 & 0.9078 & 2.4501 & 2.5698 & 0.1539 \\
\hline 8 & 0.6653 & 2.4911 & 6.0460 & 0.2490 \\
\hline 9 & 1.4311 & 3.1889 & 3.3896 & 0.2914 \\
\hline 10 & 1.5454 & 3.1667 & 4.2753 & 0.3280 \\
\hline 11 & 0.3267 & 0.3267 & 5.3197 & 0.1465 \\
\hline 12 & 0.1429 & 3.3221 & 2.9976 & 0.2211 \\
\hline 13 & 0.1848 & 0.1815 & 4.9878 & 0.0275 \\
\hline$\alpha$ & 1.0971 & 2.1105 & 3.8837 & 0.1761 \\
\hline
\end{tabular}

The best result is remarked in red color.

It can be concluded from Table 2 and Table 3 that the proposed method has a minimum detection error both in average center location and in average angle comparing to other methods. In 13 test videos, the average center location error and average angle error of this paper are 4.7867 pixels and 0.1761 degrees respectively, which are smaller than other methods. In Sequence $8,11,12$, thick clouds constructs similar color feature to sea region that attenuates the horizon. The proposed method and MSCM present the best performance in Sequence 8, 11, 12. But for other methods, they totally depart from the true horizon. Meanwhile camera mounted on board from Sequence 1 to Sequence 10 fluctuates irregularly. The gray distribution of image is disorganized. Even if under this condition, the proposed method gives the best results and can capture entire horizon accurately. In addition, the proposed method has a higher process rate in video sequences which are shown in Table 4. The experiment is executed on Matlab 2016b, CPU Intel i5-3210M, Memory 2GB.

\section{Table 4-Process rates of 4 methods}

\begin{tabular}{|c|c|c|c|c|}
\hline \multirow{2}{*}{$\begin{array}{c}\text { The size of } \\
\text { frames }\end{array}$} & \multicolumn{4}{|c|}{ Process rate (seconds per frame) } \\
\cline { 2 - 5 } & Proposed & $M S C M[9]$ & $H-P D F[3]$ & $H-D E[2]$ \\
\hline $1920 \times 1080$ & 1.021 & 6.223 & 3.556 & 7.404 \\
\hline
\end{tabular}

From Table 4, the proposed horizon detection method is more efficient with assurance of lower average center location error and angle error.

Some detection results by proposed method is illustrated in Fig. 11.
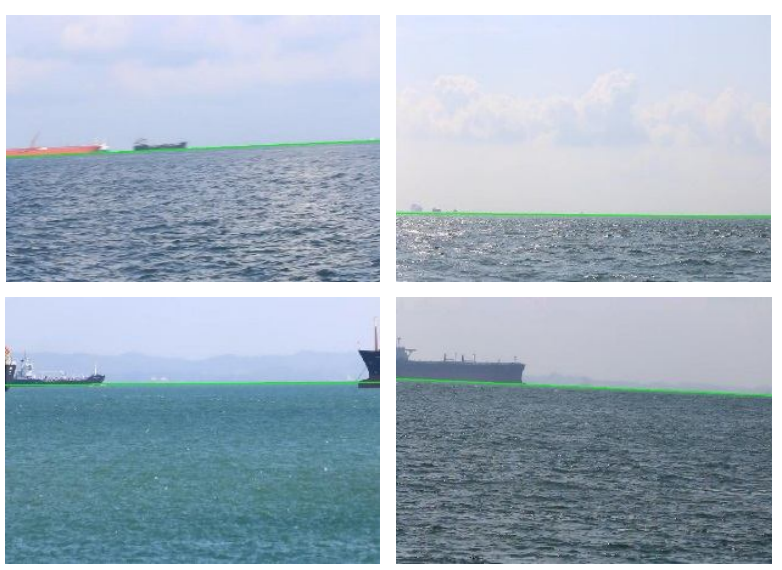

Fig. 11. Some sea-sky line detection result (in green) by proposed method

From Fig. 11, it can be found that the proposed method have a good performance in test sequences even if a part of sea-sky line is occluded by vessels.

\section{Conclusion}

In this paper, a novel horizon detection method for maritime environment is proposed. The method is based on color feature as well as textural information. It consists of sea sky region extraction and horizon detection, which is more precise and fast no matter in 
the sceneries created by camera mounted on board or on shore. New linear fitting metric is used in sea-sky line extraction. The proposed linear fitting method can rectify the outlier values. The experimental results on a sequence of test videos demonstrate that the proposed sea-sky line detection method has a higher accuracy and it is more robust and efficient than other existed methods.

REFERENCES

1. You, J.Y. \& Chien, S.I. (2008), "Saturation enhancement of blue sky for increasing preference of scenery images", IEEE Transactions on Consumer Electronics, Vol. 54, No. 2, pp. 762-768, DOI: https://doi.org/10. 1109/TCE.2008.4560158.

2. Ettinger, S.M., Nechyba, M.C., Ifju, P.G. and Waszak, M. (2004), "Vision-Guided Flight Stability and Control for Micro Air Vehicles", IEEE/RSJ International Conference on Intelligent Robots and Systems, DOI: https://doi.org/10.1109/IRDS.2002.1041582.

3. Lipschutz, I., Gershikov, E. and Milgrom, B. (2013), "New Methods for Horizon Line Detection in Infrared and Visible Sea Images", International Journal Of Computational Engineering Research, Vol. 3, Issue. 3, pp. 226-233.

4. Shen, Y.F., Krusienski, D., Li, J. and Rahman, Z. (2013), “A Hierarchical Horizon Detection Algorithm”, IEEE GEOSCI REMOTE $S, 10(1)$, pp. 111-114.

5. Cornall, T.D., Egan, G.K. (2006), "Aircraft Attitude Estimation from Horizon Video", Electron LETT, 42 (12), pp. $744-745$.

6. Zhang, H., Yin, P., Zhang, X.O. and Shen, X.R. (2011), “A Robust Adaptive Horizon Recognizing Algorithm Based on Projection", TI MEAS CONTROL, 33(6), pp. 734-751.

7. Luom J. and Etzm S. (2002), "A Physics-Motivated Approach to Detecting Sky”, Photographs. International Conference on Pattern Recognition, pp. 155-158.

8. Singhal, A. and Luo, J.B. (2003), "Hybrid Approach to Classifying Sky Regions in Natural Images", Image and Video Communication and Processing, pp. 562-572.

9. Prasad, D.K., Rajan, D, Prasath, C.K., Rachmawati, L., Rajabally, E. and Quekm C, (2016), "MSCM-LiFe: Multi-scale Cross Modal Linear Feature for Horizon Detection", Maritime Images. TENCON, pp. 1366-1370.

10. Otsu, N. (1979), "A Threshold Selection Method from Gray-Level Histograms", IEEE Transactions on Systems, Man, and Cybernetics, 9(1), pp. 62-66, DOI: https://doi.org/10.1109/TSMC.1979.4310076.

Received (Надійшла) 11.09.2018

Accepted for publication (Прийнята до друку) 14.11.2018

\section{Алгоритм розпізнавання морського горизонту на фото і відеозображеннях}

О. В. Шматко, В. О. Алексієв, Лианг Донг

Предметом дослідження $є$ процес виявлення лінії морського горизонту, заснований на кольоровій характеристиці. Мета цієї роботи полягає в розробці методу заснованого на функції обробки кольорової інформації, а також текстурної інформації. Він полягає в поділі області моря і неба і виявлення горизонту. Метод є більш точним і швидким, незалежно від того, які знімки зроблені камерою, встановленою на борту або на березі. Завдання, які необхідно вирішити запропонувати нову лінійну метрику фітингу при визначенні лінії морського горизонту. Були отримані наступні результати: вивчено пропонований метод лінійної підгонки. Виконано оцінку запропонованого методу виявлення горизонту в порівнянні з іншими трьома сучасними методами, заснованими на 13 складних тестових відеороликах в різних обставинах. 3 метода: метод, заснований на дискримінантах і власних значеннях коваріаційних матриць в просторі RGB (H-DE); метод, який використовує функції розподілу ймовірностей області моря і неба (H-PDF) i метод багатомасштабного крос-модального лінійного ознаки (MSCM). Дані, використані при дослідженнях можна розділити на дві категорії: камера, встановлена на борту, і камера, встановлена на березі. Висновок. Пропонований метод лінійної підгонки може виправити значення викидів. Експериментальні результати за послідовністю тестових відео показують, що пропонований метод виявлення лінії морського горизонту має більш високу точність і є більш надійним та ефективним, ніж інші існуючі методи.

Ключові слова: лінія морського горизонту; точне визначення лінії морського горизонту для зображень 3 низьким дозволом; новий метод виявлення морського горизонту.

\section{Алгоритм распознавания морского горизонта на фото и видеоизображениях}

А. В. Шматко., В. О. Алексеев, Ліанг Донг

Предметом исследования является процесс обнаружения линии морского горизонта, основанный на цветовой характеристике. Цель этой работы заключается в разработке метода основанного на функции обработки цветовой информации, а также текстурной информации. Он заключается в разделении области моря и неба и обнаружения горизонта. Метод является более точным и быстрым, независимо от того, какие снимки сделаны камерой, установленной на борту или на берегу. Задачи, которые необходимо решить - предложить новую линейную метрику фитинга при определении линии морского горизонта. Были получены следующие результаты: изучен предлагаемый метод линейной подгонки. Выполнена оценка предложенного метода обнаружения горизонта по сравнению с другими тремя современными методами, основанными на 13 сложных тестовых видеороликах в разных обстоятельствах. 3 метода: метод, основанный на дискриминантах и собственных значениях ковариационных матриц в пространстве RGB (H-DE); метод, использующий функции распределения вероятностей области моря и неба (H-PDF) и метод многомасштабного кросс-модального линейного признака (MSCM). Данные, использованные при исследованиях можно разделить на две категории: камера, установленная на борту, и камера, установленная на берегу. Выводы. Предлагаемый метод линейного подгонки может исправить значения выбросов. Экспериментальные результаты по последовательности тестовых видео показывают, что предлагаемый метод обнаружения линии морского горизонта имеет более высокую точность и является более надежным и эффективным, чем другие существующие методы.

Ключевые слов а: линия морского горизонта; точное определение линии морского горизонта для изображений с низким разрешением; новый метод обнаружения морского горизонта. 